\title{
Pharmacological Characterization of RS-1259, an Orally Active Dual Inhibitor of Acetylcholinesterase and Serotonin Transporter, in Rodents: Possible Treatment of Alzheimer's Disease
}

\author{
Yasuyuki Abe ${ }^{1, *}$, Atsushi Aoyagi ${ }^{1}$, Takao Hara ${ }^{1}$, Kazumi Abe $^{1}$, Reina Yamazaki ${ }^{1}$, Yoshihiro Kumagae ${ }^{1}$, \\ Shunji Naruto ${ }^{2}$, Kazuo Koyama ${ }^{2}$, Shinji Marumoto ${ }^{2}$, Keiko Tago $^{2}$, Narihiro Toda ${ }^{2}$, Kazuko Takami ${ }^{2}$, \\ Naho Yamada ${ }^{2}$, Mayuko Ori ${ }^{2}$, Hiroshi Kogen ${ }^{2}$, and Tsugio Kaneko ${ }^{1}$ \\ ${ }^{l}$ Neuroscience and Immunology Research Laboratories and ${ }^{2}$ Exploratory Chemical Research Laboratories, \\ Sankyo Co., Ltd., 2-58, Hiromachi 1-chome, Shinagawa-ku, Tokyo 140-8710, Japan
}

Received March 31, 2003; Accepted July 8, 2003

\begin{abstract}
A dual inhibitor of acetylcholinesterase (AChE) and serotonin transporter (SERT), RS-1259 (4-[1S)-methylamino-3-(4-nitrophenoxy)]propylphenyl N,N-dimethylcarbamate (fumaric acid) $)_{1 / 2}$ salt), was newly synthesized. RS-1259 simultaneously inhibited AChE and SERT in the brain following an oral administration in mice and rats. Actual simultaneous elevation of extracellular levels of 5-HT and ACh in the rat hippocampus was confirmed by microdialysis. The compound was as effective as SERT inhibitors such as fluoxetine and fluvoxamine in a 5hydroxytryptophan-enhancing test in mice. Spatial memory deficits in the two-platform task of a water maze in aged rats were ameliorated by RS-1259 as well as donepezil. Both RS-1259 and donepezil increased the awake episodes in the daytime electroencephalogram of rats. Although RS-1259 was weaker than donepezil in enhancing central cholinergic transmission, as observed by ACh elevation in the hippocampus and memory enhancement in aged rats, the efficacy of RS-1259 on the consciousness level, which reflects the whole activity in the brain, was almost the same as that of donepezil. These results suggest that both cholinergic and serotonergic systems are involved in maintaining brain arousal and that a dual inhibitor of AChE and SERT may be useful for the treatment of cognitive disorders associated with reduced brain activity such as in Alzheimer's disease.
\end{abstract}

Keywords: acetylcholinesterase, serotonin transporter, cerebral activation, Alzheimer's disease, rodent

\section{Introduction}

The central cholinergic system is known to play a fundamental role in cognitive function, and extensive evidence indicates that a disruption of the cholinergic function leads to characteristic signs of aging and Alzheimer's disease (AD) $(1,2)$. Today, acetylcholinesterase (AChE) inhibitors such as tacrine (3), donepezil (4), rivastigmine (5), and galanthamine (6) are the only approved medication for AD patients. However, their clinical usefulness is limited, largely because of adverse events arising from excessive activation of cholinergic

*Corresponding author. FAX: +81-3-5436-8572

E-mail: yasuabe@shina.sankyo.co.jp systems (7).

Recent research suggests that cholinergic dysfunction does not provide a complete account of age-related cognitive deficits $(8,9)$. Hypofunction of several other neuronal systems such as the glutamatergic, GABAergic, and monoaminergic systems in the brain of AD patients, which has also been reported (10), may be partly responsible for the cognitive decline. Accordingly, there are many experimental reports suggesting that several neurotransmitters, including serotonin, norepinephrine, dopamine, and GABA, appear to play a role in cognitive processes and interact with the cholinergic systems (11). Moreover, AD patients often exhibit several behavioral abnormalities such as irritability, anxiety, and depres- 
sion, as well as cognitive impairment $(12-14)$. It is reported that depression is present in about $40 \%$ of patients with dementia (15). This has led to several clinical trials being conducted for psychotropic drugs to treat the behavioral symptoms of AD patients $(16-19)$. Co-administration of sertraline, a selective inhibitor of serotonin transporter (SERT), with donepezil has been proven to be favorable over placebo in treating $A D$ patients with behavioral symptoms (20). However, a major disadvantage of the combination of varying drug classes is that compounds with different pharmacodynamic and pharmacokinetic properties may be difficult to manage clinically. Moreover, they may cause a detrimental drug-drug interaction as well $(21,22)$.

To circumvent these disadvantages, we attempted to develop a new agent that simultaneously inhibits AChE and SERT for the treatment of AD (23). So far, two potent cholinesterase inhibitors that show moderate activities on monoaminergic systems in vitro have been reported $(24,25)$, but no compound has been reported to show simultaneous activation of the cholinergic and monoaminergic transmissions in the brain in vivo, probably due to the toxic overstimulation of the cholinergic neurotransmission prior to the appearance of the monoaminergic effect. Here, we report the pharmacological properties of RS-1259, a newly synthesized dual inhibitor of AChE and SERT in rodents. Preliminary results have been presented in an abstract form (26).

\section{Materials and Methods}

Experiments were performed in accordance with the Guiding Principles for the Care and Use of Laboratory Animals approved by The Japanese Pharmacological Society and also in accordance with Sankyo's Code of Ethical Research.

\section{Animals}

Male ddY mice (4-week-old; SLC, Shizuoka) were used for the ex vivo determination of AChE and SERT inhibition in the brain and the 5-hydroxy-L-tryptophan (5-HTP)-enhancing test. Male Sprague-Dawley (8week-old; Charles River Japan, Yokohama), male Wistar (10 - 13-week-old, SLC) and male F344 (2425-month-old, Charles River Japan) rats were used for the microdialysis of the hippocampus, the daytime electroencephalogram (EEG), and the water maze, respectively. The animals were housed for at least one week before use in breeding rooms (lighted: 7:0019:00) in which the room temperature and humidity were maintained at $22-24^{\circ} \mathrm{C}$ and $50-70 \%$, respectively. Food and water were consumed ad libitum.

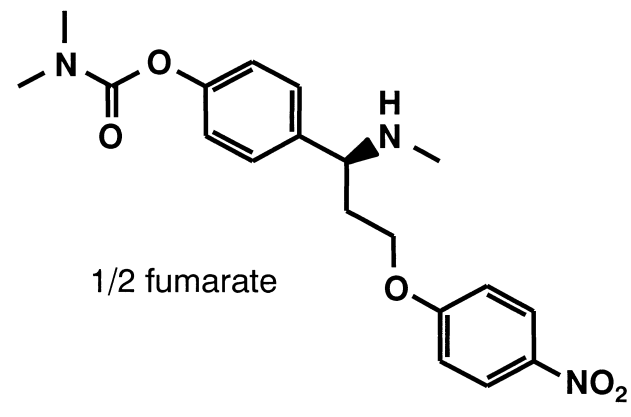

RS-1259:

4-[(1S)-methylamino-3-(4-nitrophenoxy)] propylphenyl $\mathrm{N}, \mathrm{N}$-dimethylcarbamate (fumaric acid) ${ }_{1 / 2}$ salt

Fig. 1. Chemical structure of RS-1259.

\section{Chemicals}

RS-1259 (4-[(1S)-methylamino-3-(4-nitrophenoxy)] propylphenyl $N, N$-dimethylcarbamate (fumaric acid) $)_{1 / 2}$ salt; Fig. 1) was synthesized in the Exploratory Chemical Research Laboratories, Sankyo Co., Ltd. Donepezil $\mathrm{HCl}$ and rivastigmine tartrate were synthesized at Chemtech Labo., Inc. (Tokyo). Fluoxetine $\mathrm{HCl}$ and fluvoxamine maleate were purchased from Tocris Cookson, Ltd. (Avonmouth, UK). S-(-)-carbidopa and 5-HTP were purchased from Sigma Chemical Co. (St. Louis, MO, USA). The compounds were dissolved in distilled water or suspended in $0.5 \%$ tragacanth gum (Wako Pure Chemical Industries, Ltd., Osaka) solution for oral administration and were dissolved in physiological saline for injection. The systemic doses were expressed as the salt forms. Drug solutions were administered at a constant volume of 1 and $10 \mathrm{ml} / \mathrm{kg}$ of body weight to rats and mice, respectively. $\left[{ }^{3} \mathrm{H}\right]$ Serotonin, $\left[{ }^{3} \mathrm{H}\right]$ noradrenaline, and $\left[{ }^{3} \mathrm{H}\right]$ dopamine were purchased from New England Nuclear (Boston, MA, USA). $\left[{ }^{3} \mathrm{H}\right]$ Citalopram was purchased from NEN Life Science Products (Boston, MA, USA).

\section{AChE inhibition in the brain homogenate of mice and rats}

AChE activity was measured in duplicate by the spectrophotometric method of Ellman et al. (27) with some modifications. Brain homogenate was used as the enzyme source. The whole brain except for the cerebellum was homogenized in 9 volumes of $100 \mathrm{mM}$ sodium phosphate buffer ( $\mathrm{pH}$ 7.0). Homogenates were stored at $-80^{\circ} \mathrm{C}$ until analysis. The test compounds were dissolved in dimethyl sulphoxide (DMSO) and $10 \mu \mathrm{l}$ of the solution was added to $3 \mathrm{ml}$ of the buffer containing $10 \mu 1$ of the brain homogenate. The mixture was incubated for 10 and $20 \mathrm{~min}$ at room temperature before and after adding $50 \mu 1$ of dithiobisnitrobenzoate (DTNB), 
respectively. The absorbance at $412 \mathrm{~nm}$ was measured (U-1080; Hitachi Ltd., Tokyo) immediately and $8 \mathrm{~min}$ after adding $50 \mu \mathrm{l}$ of acetylthiocholine (ATC). The AChE activity was expressed as a change in OD at $412 \mathrm{~nm}$.

Uptake inhibition of serotonin (5-HT), noradrenaline $(N A)$, and dopamine (DA) in the rat synaptosome

The whole brain except for the cerebellum was homogenized in $100 \mathrm{mM}$ sodium phosphate buffer ( $\mathrm{pH} 7.0$ ). The homogenate was centrifuged at $1,000 \times g$ for $10 \mathrm{~min}$ and the supernatant was recentrifuged at $20,000 \times g$ for $20 \mathrm{~min}$ at $4^{\circ} \mathrm{C}$. The pellet was suspended in $100 \mathrm{mM}$ ice-cold sodium phosphate buffer $(\mathrm{pH} 7.0)$. After preincubation of $1 \mathrm{ml}$ of the synaptosome suspension with $10 \mu 1$ of the test compound (in DMSO) at $37^{\circ} \mathrm{C}$ for $5 \mathrm{~min}, 10 \mu \mathrm{l}$ of $\left[{ }^{3} \mathrm{H}\right] 5-\mathrm{HT}(100 \mathrm{nM}),\left[{ }^{3} \mathrm{H}\right] \mathrm{NA}(100 \mathrm{nM})$, or $\left[{ }^{3} \mathrm{H}\right] \mathrm{DA}(100 \mathrm{nM})$ was added and the mixture was incubated at $37^{\circ} \mathrm{C}$ for another $5 \mathrm{~min}$. Adding $4 \mathrm{ml}$ of ice-cold saline solution terminated the uptake of transmitters into the synaptosome. The reaction mixture was filtrated on a Whatman GF/B filter that was then washed with $4 \mathrm{ml}$ of ice-cold saline solution once. The radioactivity retained on the filter was measured by a liquid scintillation counter. The blank was determined by measuring the uptake of $\left[{ }^{3} \mathrm{H}\right] 5-\mathrm{HT},\left[{ }^{3} \mathrm{H}\right] \mathrm{NA}$, or $\left[{ }^{3} \mathrm{H}\right] \mathrm{DA}$ at $4^{\circ} \mathrm{C}$ for $5 \mathrm{~min}$. All the determinations were performed in duplicate.

The in vitro profiles of RS-1259 with respect to receptor binding, transporter inhibition, and enzyme inhibition were evaluated in MDS Pharma Services as a contract study.

\section{Inhibition of brain AChE and SERT following oral administration}

Animals were instantly decapitated at $0.25,0.5,1,2$, 4,8 , and $24 \mathrm{~h}$ after oral administration of test compounds. Forebrains were removed and stored at $-80^{\circ} \mathrm{C}$ until analysis. All determinations were performed in duplicate.

The brain was homogenized in 1.6 volumes of $100 \mathrm{mM}$ sodium phosphate buffer $(\mathrm{pH} \mathrm{7.0)}$ for the determination of AChE activity by the spectrophotometric method. Of the homogenate, $100 \mu \mathrm{l}$ was incubated at room temperature for $60 \mathrm{~s}$ with $10 \mu \mathrm{l}$ of $60 \mathrm{mM}$ ATC or $100 \mu 1$ of $1 \mathrm{~N}$ perchloric acid (PCA) (used as a blank). The reaction was terminated by adding $100 \mu \mathrm{l}$ of PCA or $10 \mu \mathrm{l}$ of ATC, respectively, and the homogenate was centrifuged at $10,000 \times g$ for $10 \mathrm{~min}$ at $20^{\circ} \mathrm{C}$. In a 96-well plate, 5- $\mu 1$ samples of each supernatant were incubated with $150 \mu \mathrm{l}$ of DTNB for $20 \mathrm{~min}$ at room temperature and then the absorbance at $415 \mathrm{~nm}$ was measured.
The brain was homogenized in 3 volumes of $50 \mathrm{mM}$ Tris-HCl buffer ( $\mathrm{pH}$ 7.7) for the SERT inhibition measurement as determined by the displacement of $\left[{ }^{3} \mathrm{H}\right]$ citalopram binding. Of the homogenate, $250 \mu \mathrm{l}$ was incubated with $10 \mu \mathrm{l}$ of $\left[{ }^{3} \mathrm{H}\right]$ citalopram $(0.77 \mathrm{nM})$ at $25^{\circ} \mathrm{C}$ for $60 \mathrm{~min}$ with or without $1 \mathrm{mM}$ of fluvoxamine. The incubated mixture was centrifuged at $3,000 \times g$ for $6 \mathrm{~min}$ at $4^{\circ} \mathrm{C}$ after adding $2.5 \mathrm{ml}$ of Tris- $\mathrm{HCl}$ buffer ( $\mathrm{pH}$ 7.7). The pellet was resuspended in $2.5 \mathrm{ml}$ of the buffer and the suspension was centrifuged at 3,000 $\times g$ for $6 \mathrm{~min}$ at $4^{\circ} \mathrm{C}$. Then, the pellet was suspended in $1 \mathrm{ml}$ of the buffer and the radioactivity was measured by a liquid scintillation counter.

\section{Microdialysis of the rat hippocampus}

Rats were anesthetized with an intraperitoneal injection of $50 \mathrm{mg} / \mathrm{kg}$ of pentobarbital $\mathrm{Na}\left(\mathrm{Nembutal}^{\circledR}\right.$; Abbott Laboratories, Abbott Park, IL, USA) and fixed to a stereotaxic apparatus. A probe (CMA/10; BAS, Inc., Tokyo) was implanted into the hippocampus according to the brain atlas of Paxinos and Watson (28) (AP -5.5, ML +5.0, depth -6.0 from the dura mater). One day after the probe-implantation, the rat was fixed to the microdialysis device under anesthesia with isoflurane (FORANE ${ }^{\circledR}$, Abbott). Modified Krebs-Ringer solution (145 mM NaCl, $1.2 \mathrm{mM} \mathrm{CaCl}_{2}, 2.7 \mathrm{mM} \mathrm{KCl}$, $1.0 \mathrm{mM} \mathrm{MgCl}_{2}, 0.2 \mathrm{mM}$ ascorbic acid, and $2 \mathrm{mM}$ phosphate buffer ( $\mathrm{pH} 7.4)$ ) was perfused into the dialysis probe and the dialysate was collected every $60 \mathrm{~min}$ after the anesthesia had been ceased for more than $1 \mathrm{~h}$, with a flow rate of $2 \mu \mathrm{l} / \mathrm{min}$. Then the test compounds were administered orally. ACh and 5-HT were assayed using an HPLC system (LC-10AD; Shimadzu Co., Kyoto) equipped with an electrochemical detector (LC-4C, BAS Inc.). For the determination of 5-HT, $20 \mu \mathrm{l}$ of the collected dialysate was injected into the HPLC system. An Eicompak CA-5ODS column with a pre-column $(4.6 \phi \times 150 \mathrm{~mm}$; Eicom Co., Kyoto $)$ was used and kept at $30^{\circ} \mathrm{C}$. The mobile phase consisted of $0.1 \mathrm{M}$ phosphate buffer ( $\mathrm{pH} 6.0), 50 \mathrm{mg} / 1$ EDTA, $240 \mathrm{mg} / 1$ sodium 1-octanesulfonate, and 20\% methanol; and the flow rate was $0.23 \mathrm{ml} / \mathrm{min}$. The potential of the detector was set at $400 \mathrm{mV}$. For the determination of $\mathrm{ACh}$, the internal standard, $30 \mu \mathrm{l}$ of $0.5 \mu \mathrm{M}$ ethyl homocholine, was added to $90 \mu$ l of the dialysate and a $100-\mu 1$ aliquot of the mixture was injected into the HPLC system. A separation column with a pre-column (AC-Gel, Eicom Co.) and an enzyme column (ACEnzympak, Eicom Co.) kept at $35^{\circ} \mathrm{C}$ were used. The mobile phase consisted of $0.1 \mathrm{M}$ phosphate buffer (pH 8.5), $240 \mathrm{mg} / 1$ sodium 1-decanesulfonate, and $65 \mathrm{mg} / 1$ tetramethylammonium chloride; and the flow rate was $0.6 \mathrm{ml} / \mathrm{min}$. The potential of the detector was 
set at $450 \mathrm{mV}$.

\section{5-HTP-enhancing test in mice}

Mice were separately placed in transparent acrylic resin-cages $(19-\mathrm{cm} \mathrm{W}, 19-\mathrm{cm} \mathrm{L}$, and $20-\mathrm{cm} \mathrm{H})$ that were set in a locomotion counting apparatus (Scanet MV10TW; Toyosangyo Co., Toyama). Mice were allowed to explore their surroundings beforehand for more than $30 \mathrm{~min}$. $S$-(-)-Carbidopa $(20 \mathrm{mg} / \mathrm{kg}$, i.p. $)$ and 5 -HTP $(50 \mathrm{mg} / \mathrm{kg}$, s.c.) were injected $15 \mathrm{~min}$ and $30 \mathrm{~min}$ after an oral administration of the test compound, respectively. The locomotion count, which was defined as passing a set of infrared beams, of each mouse was measured for $120 \mathrm{~min}$ after the 5-HTP injection. The mice were allocated to four groups of 8 mice to prepare the control and 3 dosage groups for each test compound. The locomotion count measured every $30 \mathrm{~min}$ in the 4 groups was statistically analyzed by the ANOVA of repeated measures followed by Fisher's PLSD method for a comparison between the control and each dose group. The StatView + Graphics4.1J (Abacus Concepts, Inc., Berkeley, CA, USA) was used for the statistical processing.

\section{Water maze test in aged rats}

Pretraining: Thirteen rats were used in the behavioral tests. Pretraining for the two-platform task (TPT) was conducted as previously described $(29,30)$, starting at 2 months of age. In brief, after 2 days of daily handling, rats were trained in the place navigation task (PNT); that is, they were trained to find a submerged platform (diameter: $12 \mathrm{~cm}$ ) in a circular pool (diameter: $1.5 \mathrm{~m}$ ) at a rate of 6 trials per day. The platform location was pseudorandomly changed each day, so that on the first trial of the day, the rats had no information about where the platform was located. This pretraining shortened the period necessary for the following TPT training and improved the selection accuracy. Within 12 days of the PNT training, all rats fulfilled the criterion of reaching the platform by swimming a distance less than $300 \mathrm{~cm}$ in Trials $2-6$ for 3 consecutive days.

TPT: The TPT was conducted as previously described $(29,30)$ with some modifications. Briefly, two visible platforms of identical appearance (diameter: $12 \mathrm{~cm}$ ), one fixed and the other floating, were simultaneously placed at the center of two non-neighboring quadrants (e.g., north and south) in the same pool as that in the pretraining. The surfaces of the platforms were set $0.5-\mathrm{cm}$ above the water surface. A trial began by releasing a rat into the water facing the wall of the pool from one of the remaining two quadrants. The various patterns of platform locations and start positions are shown in Fig. 5A. One session consisting of 6 trials was given each day. Rats were released alternately from the 2 start positions. The trial ended when the rat reached either platform. The selection accuracy was defined as the percentage of correct responses (i.e., choosing the fixed platform first) in Trials $2-6$ for each session. The first trial served as an informational trial for the location of the fixed platform. More than 20 sessions of the TPT training were done for each rat, and the success rate of all 13 animals increased asymptomatically with a selection accuracy of $75-80 \%$. The selection accuracy established for each rat could be maintained by periodical trainings (approximately 3 sessions per month) for 16 months. At $18-20$ months of age, the selection accuracy gradually declined with age as previously reported (31). At $24-25$ months of age, 11 out of 13 rats showing a decline in the TPT performance were divided into one vehicle and three treatment groups of the two test compounds at different doses and used on a rotational basis for two experiments. There was at least a 2-day washout period between each drug test to ensure the absence of influence of the previous drug. The swimming distance, the swimming speed, the floating time, and the swimming time were measured simultaneously for each trial. The tests for the vehicle and three drugtreated groups were carried out over four days. The results of the four tests for each group (vehicle and dose groups) were pooled and analyzed by the one-tailed Wilcoxon's Ranked-Sums test.

\section{Consciousness levels of freely-moving rats in daytime EEG}

Under anesthesia with pentobarbital-Na (Nembutal ${ }^{\circledR}$; $50 \mathrm{mg} / \mathrm{kg}$, i.p.), rats were fixed to a stereotaxic apparatus. A pair of twisted wire electrodes insulated except at their tips (diameter: $0.17 \mathrm{~mm}$, interpolar distance: $0.5 \mathrm{~mm}$ ) was inserted into the dorsal hippocampus according to the brain atlas by Fifkova and Marsala (32). Another pair of stainless wire electrodes (diameter: $0.15 \mathrm{~mm}$ ) covered with silicone tubing except for $5-$ $10 \mathrm{~mm}$ of length from the tip was inserted into the neck muscle to record the electromyogram (EMG). In addition, a pair of silver-ball electrodes (diameter: 0.5 $1.0 \mathrm{~mm}$ ) was implanted into the skull over the sensorymotor cortex. These electrodes and an anchor screw were fixed on the skull with dental cement and acrylic resin.

After a recovery period of at least one week, the EEG and EMG were recorded (EEG-3118, Nihon Kohden) from 9:00 to 16:00 continuously. The animals were placed in a cage, which was set in a sound-proof, shielded room with food and water, $16-17 \mathrm{~h}$ prior to the recording. The general behavior of each animal was recorded on a video tape recorder (AG220D; Matsushita 
Electric, Osaka). After an hour of baseline recordings, the test compound or distilled water was orally administered. The consciousness level of the animals defined as an awake, slow wave sleep or paradoxical sleep episode was determined based on the EEG and EMG patterns.

\section{Statistical analyses}

Pharmacological results were represented as the mean and S.E.M. The difference between the means was determined by ANOVA followed by Dunnett's $t$-test unless otherwise stated. The statistical significance level was set at $P<0.05$.

\section{Results}

In vitro profiles of $R S-1259$

AChE inhibition was measured in the homogenate of the mouse brain. The $50 \%$ inhibitory concentration $\left(\mathrm{IC}_{50}\right)$ of RS-1259 was $105 \mathrm{nM}$, which was $10-20$ times weaker than that for donepezil. The $\mathrm{IC}_{50}$ of rivastigmine was extremely high in the assay system. For the uptake of 5-HT, NA, and DA measurement in the rat synaptosome, RS-1259 specifically inhibited 5-HT uptake with an $\mathrm{IC}_{50}$ of $90 \mathrm{nM}$, which was twice as potent as that of fluoxetine. The $\mathrm{IC}_{50}$ values of $\mathrm{RS}-1259$ for the NA and DA uptake were more than $1 \mu \mathrm{M}$, whereas those of imipramine and GBR12909 were 46 and $4 \mathrm{nM}$ in the assay system (Table 1).

The binding affinity for receptors such as nicotinic and muscarinic ACh, 5-HT, NA, DA, histamine, glutamate, GABA, glycine, and opiate receptors and the $\mathrm{IC}_{50}$ values of RS-1259 against choline, adenosine, GABA transporters, and choline acetyltransferase (ChAT) were more than $10 \mu \mathrm{M}$. RS-1259 was reported by MDS Pharma Services to show weak affinities to NA transporters $\left(\mathrm{IC}_{50}=7.7 \mu \mathrm{M}\right)$, L-type $\mathrm{Ca}^{2+}$ channels (3.6 $\mu \mathrm{M})$, sigma receptors $(2 \mu \mathrm{M})$, and $\mathrm{Na}^{+}$channels

\section{(5.1 $\mu \mathrm{M})$ (data not shown).}

\section{Ex vivo inhibition of AChE and SERT}

RS-1259 inhibited AChE and SERT in the brain of mice (Fig. 2A and Table 2) and rats (Table 2) dosedependently following oral administration. The doses necessary for $50 \%$ efficacy $\left(\mathrm{ED}_{50}\right)$ of $\mathrm{RS}-1259$, donepezil, and rivastigmine were larger in rats than those in mice, although the potency order of compounds was the same in each species. RS-1259 was as potent as fluoxetine and more potent than fluvoxamine for SERT inhibition ex vivo in mice.

After oral administration, RS-1259 inhibited AChE and SERT in the mouse brain in a similar manner over time. The inhibition of AChE and SERT reached a maximum at $1-2 \mathrm{~h}$, was still observed at $8 \mathrm{~h}$ and fully disappeared by $24 \mathrm{~h}$ after administration. The time to reach maximum AChE inhibition and the duration of the inhibitory effect by donepezil were much shorter than that of RS-1259 in mice (Fig. 2B).

\section{Microdialysis in the rat hippocampus}

RS-1259 simultaneously elevated extracellular levels of ACh and 5-HT in the hippocampus of freely moving rats. Donepezil and fluoxetine only increased $\mathrm{ACh}$ and 5-HT levels, respectively (Fig. 3: A and B). ACh was increased to a similar extent by RS-1259 and donepezil at doses of 64 and $16 \mathrm{mg} / \mathrm{kg}$, respectively. At such high doses, all rats showed cholinergic symptoms such as muscle fasciculation, salivation, and lacrimation. The rate of 5-HT increase induced by fluoxetine at a dose of $32 \mathrm{mg} / \mathrm{kg}$ was slower and the overall $5-\mathrm{HT}$ values were lower than those by RS-1259 at $64 \mathrm{mg} / \mathrm{kg}$. The flat body posture elicited by fluoxetine could not be distinguished from the abnormal posture resulting from the cholinergic symptom that was observed when rats were treated with RS-1259.

Table 1. In vitro activities $\left(\mathrm{IC}_{50}\right)$ of RS-1259 in comparison with those of reference compounds

\begin{tabular}{lccccc}
\hline & \multicolumn{4}{c}{ IC $_{50}$ values $(\mathrm{nM})$} \\
\cline { 2 - 5 } & AChE & & 5-HT uptake & NA uptake & DA uptake \\
\cline { 2 - 5 } \cline { 5 - 6 } & mouse brain & & rat synaptosome \\
\hline RS-1259 & 105 & & $>1000$ & $>1000$ \\
Donepezil & $5-10^{\#}$ & & n.d. & n.d. & n.d. \\
Rivastigmine & 11,000 & & n.d. & n.d. & n.d. \\
Fluoxetine & n.d. & & 180 & 840 & n.d. \\
Imipramine & n.d. & n.d. & 46 & n.d. \\
GBR12909 & n.d. & n.d. & n.d. & 4 \\
\hline
\end{tabular}

n.d.: not determined. "Donepezil was always added as an internal standard of the AChE inhibition assay; the numbers represent a range of $\mathrm{IC}_{50}$ values. 

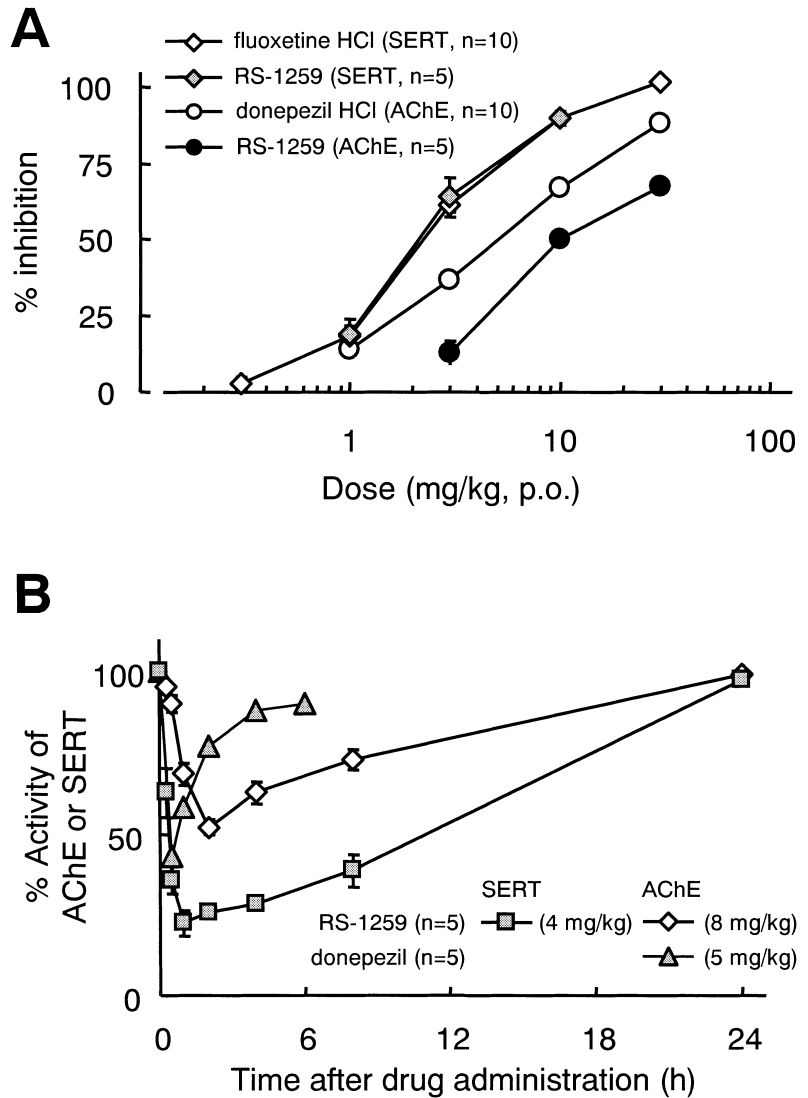

Fig. 2. Dose-dependency (A) and time course (B) of inhibition of $\mathrm{AChE}$ and SERT in the mouse brain following oral administration of RS-1259, donepezil, and fluoxetine. Ex vivo inhibition was measured at $60 \mathrm{~min}(\mathrm{~A})$ and at other time points (B) after administration. Symbols represent the mean of 5 animals, with the S.E.M.

\section{5-HTP-enhancement in mice}

RS-1259 enhanced 5-HTP-induced locomotor activity in a bell-shaped dose-response relationship with maximum enhancement at $8 \mathrm{mg} / \mathrm{kg}$ (Fig. 4A). The locomotor
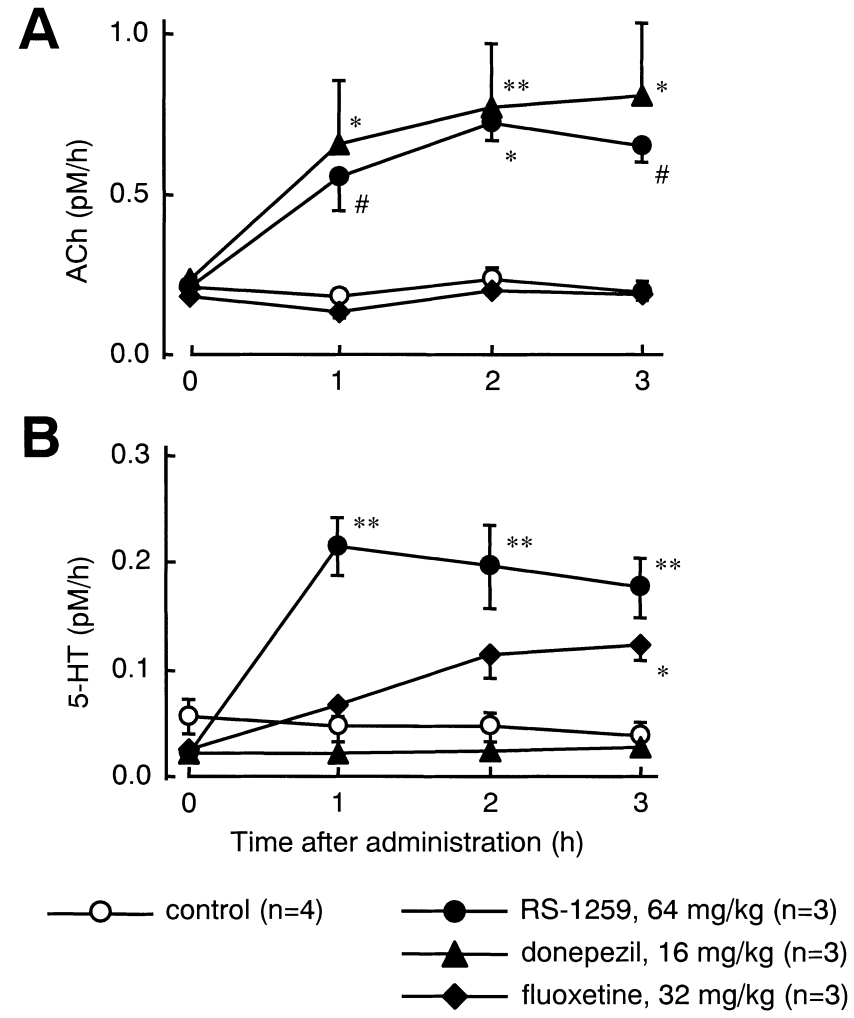

Fig. 3. Increase in extracellular concentrations of ACh (A) and 5-HT (B) in the hippocampus induced by RS-1259, donepezil, and fluoxetine in rats. Compounds or the vehicle was orally administered just after the first sampling $(-60-0 \mathrm{~h})$. Each symbol represents the mean of 3-4 animals, with the S.E.M. indicated by a bar. Where S.E.M. bars are not shown, they lie within the dimensions of the symbols. The values indicated by ${ }^{\#}, *$ and $* *$ are statistically different $(P<0.1,0.05$, and 0.01 , respectively) from those of the vehicle control at the corresponding time (ANOVA).

activity in mice treated with doses larger than $8 \mathrm{mg} / \mathrm{kg}$ was reduced as the cholinergic symptoms appeared. Fluoxetine (Fig. 4B) and fluvoxamine (Fig. 4C) were

Table 2. Inhibition of AChE and SERT in the brain 60 min after oral administration of RS-1259, AChE inhibitors, and SERT inhibitors in mice and rats

\begin{tabular}{lclcl}
\hline \multicolumn{5}{c}{ ED $_{50}$ values $(\mathrm{mg} / \mathrm{kg}, \mathrm{p}$. o. $)$} \\
\hline AChE & mice & \multicolumn{4}{c}{ rats } \\
\hline RS-1259 & 13 & $(11-15, \mathrm{n}=5)$ & 43 & $(31-75, \mathrm{n}=5)$ \\
Donepezil & 5.1 & $(4.6-5.6, \mathrm{n}=10)$ & 16 & $(12-21, \mathrm{n}=10)$ \\
Rivastigmine & 0.70 & $(0.64-0.77, \mathrm{n}=10)$ & 4.1 & $(2.7-7.5, \mathrm{n}=10)$ \\
\hline 5-HT uptake & mice & & rats & \\
\hline RS-1259 & 2.4 & $(1.9-2.9, \mathrm{n}=5)$ & $<8$ & $(66 \%$ inhibition at $8 \mathrm{mg} / \mathrm{kg}, \mathrm{n}=5)$ \\
Fluoxetine & 2.2 & $(2.0-2.5, \mathrm{n}=10)$ & n.d. & \\
Fluvoxamine & 4.6 & $(4.2-4.9, \mathrm{n}=10)$ & n.d. & \\
\hline
\end{tabular}

n.d.: not determined. Number represents the $\mathrm{ED}_{50}$ value with the $95 \%$ confidence interval in parentheses. 


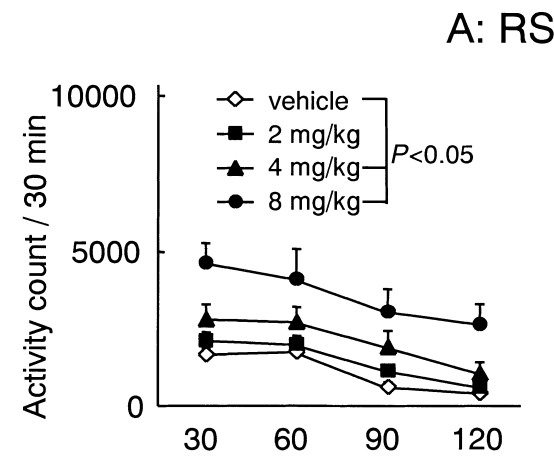

\section{B: Fluoxetine}

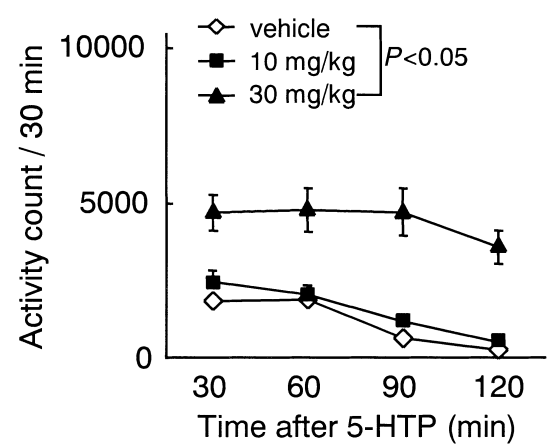

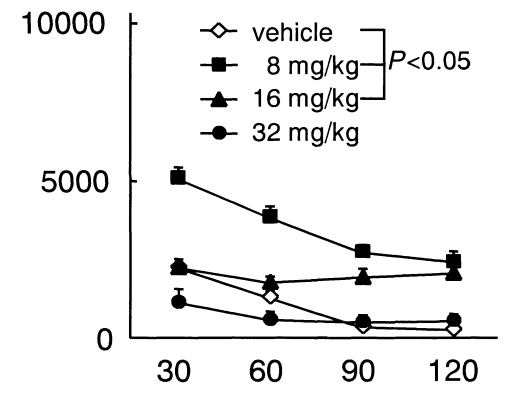

C: Fluvoxamine

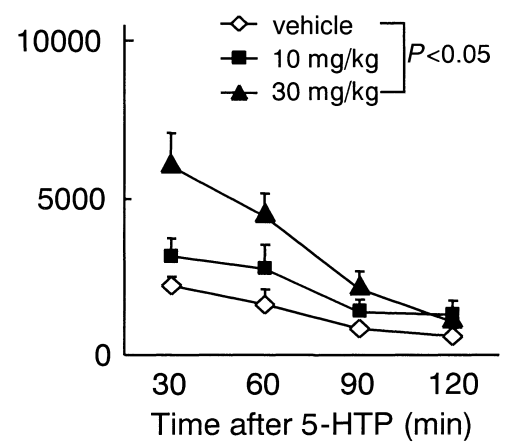

Fig. 4. 5-HTP-enhancing effect by RS-1259 (A), fluoxetine (B), and fluvoxamine (C) in mice. Each symbol represents the mean of 8 mice, with S.E.M. indicated by a bar. ANOVA of repeated measures and a post-hoc analysis, Fisher's PLSD, indicated that oral doses at 4,8 , and $16 \mathrm{mg} / \mathrm{kg}$ of RS-1259 and at $30 \mathrm{mg} / \mathrm{kg}$ of fluoxetine and fluvoxamine enhanced 5-HTP-induced locomotor activity $(P<0.05)$.

effective in the test with a longer duration of action for fluoxetine than for fluvoxamine.

\section{Amelioration of memory deficits of aged rats}

Short-term memory is severely affected early in the course of AD as well as in normal aging (33), and it is reported that short-term memory is preferentially impaired in aged animals (34). To examine whether RS1259 could reverse age-related cognitive decline, we evaluated spatial short-term memory using the TPT of a water maze in aged rats. At 24-25 months of age, 11 rats showing a significant decline in the TPT performance were orally administered AChE inhibitors or the vehicle $60 \mathrm{~min}$ before each test. In the first test, both donepezil $(0.5 \mathrm{mg} / \mathrm{kg})$ and RS-1259 $(1 \mathrm{mg} / \mathrm{kg}$, but not $0.5 \mathrm{mg} / \mathrm{kg}$ ) significantly ameliorated the aged-related short-term memory impairment (Fig. 5B). In the second test, at half the dose, donepezil $(0.25 \mathrm{mg} / \mathrm{kg})$ also improved the memory impairment, although at twice the dose $(1 \mathrm{mg} / \mathrm{kg})$ it did not (Fig. 5C). A higher dose of RS-1259 (2 mg $/ \mathrm{kg})$ was also effective in recovering the memory deficit (Fig. 5C). The parameters to evaluate sensorimotor acitivities, that is, the swimming distance, the swimming speed, the floating time, and the swimming time of rats, were not affected by the drug treatments (data not shown).

\section{Elevation of daytime consciousness level in rats}

The daytime consciousness level of rats in a familiar cage was low. The total awake $(10-20 \mathrm{~min})$, slow wave sleep (35- $45 \mathrm{~min}$ ), and paradoxical sleep (about $5 \mathrm{~min}$ ) episodes for every $60 \mathrm{~min}$ were stable during the recording period except for the initial $1 \mathrm{~h}$ when the awake episode increased and the other episodes decreased due to the handling necessary for oral administration. RS1259 and donepezil, at all doses tested, increased the awake episode and decreased slow wave sleep as well as paradoxical sleep episodes in the initial $1 \mathrm{~h}$ following oral administration (Fig. 6). The consciousness level remained elevated up to $3 \mathrm{~h}$ after the highest dose of RS-1259 was administered, whereas it returned to control levels after $2-3 \mathrm{~h}$ in rats given the highest dose of donepezil. RS-1259 was also effective for the elevation of daytime consciousness level in rats where 

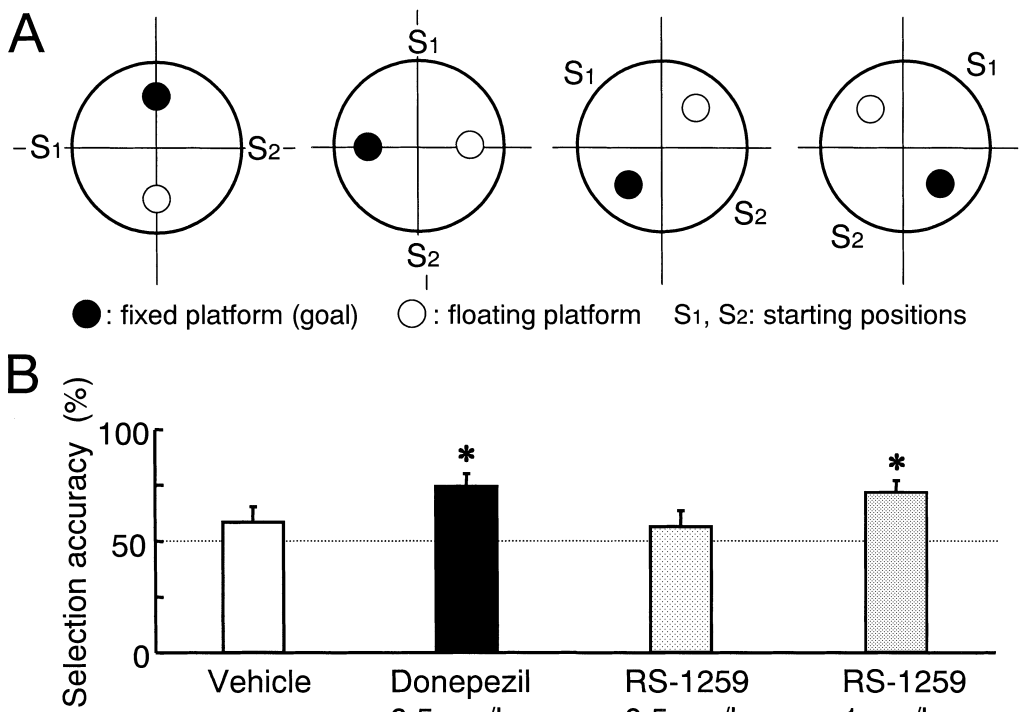

fixed platform (goal)

: floating platform $s_{1}, s_{2}:$ starting positions
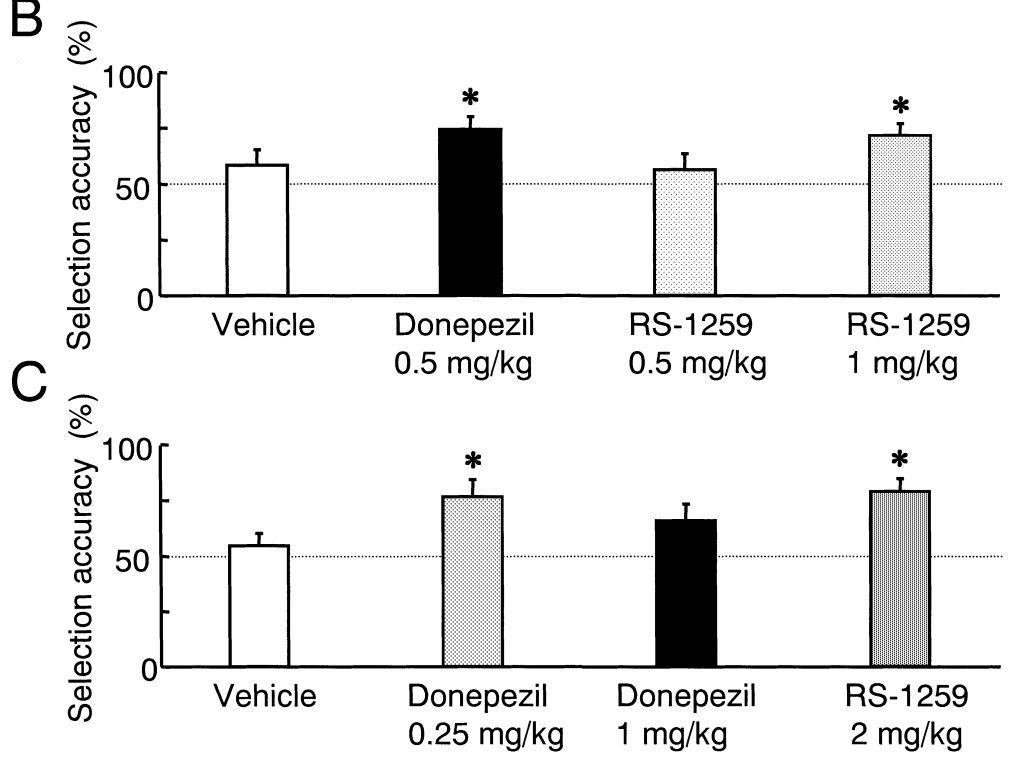

Fig. 5. Amelioration of memory deficits in aged rats by RS-1259 and donepezil. A: Four representative patterns of the platform locations and start positions are shown. Locations of the fixed platform and floating platform were randomly changed at each session. Closed circles, fixed platform; open circles, floating platform; $S_{1}$ and $S_{2}$, start positions. Panels $B$ and $C$ represent the results of two separate drug tests. Animals were orally treated with AChE inhibitors or distilled water 60 min before a test session. Each column represents the mean accuracy of 11 rats, with the S.E.M. indicated by a bar. As determined by Wilcoxon's analysis, an amelioration of the reduced accuracy by RS-1259 at 1 and $2 \mathrm{mg} / \mathrm{kg}$ and donepezil at 0.25 and $0.5 \mathrm{mg} / \mathrm{kg}$ was detected $(P<0.05)$.

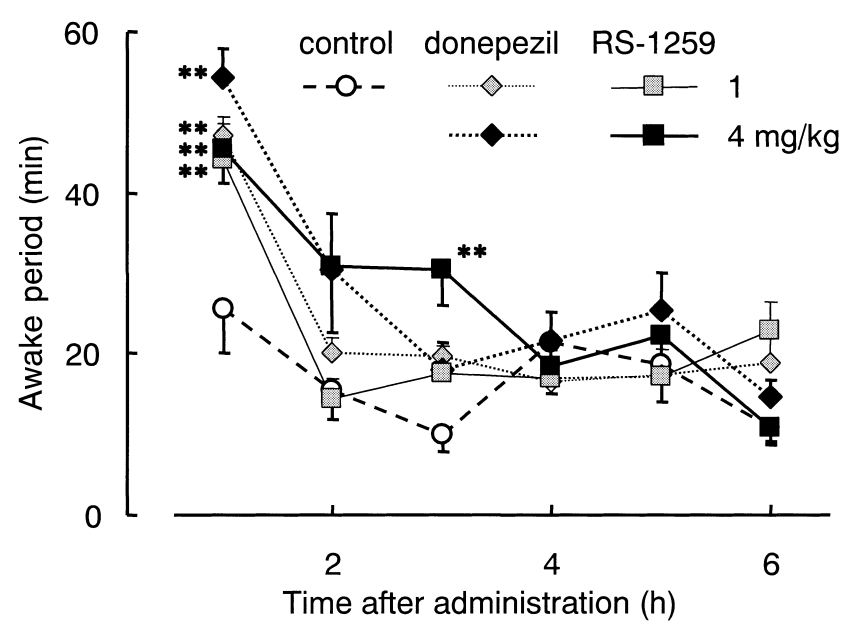

Fig. 6. Effects of RS-1259 and donepezil on the daytime consciousness level of rats. The total time of awake episodes was calculated every $60 \mathrm{~min}$ after a single oral administration of AChE inhibitors or the vehicle. Each symbol represents the mean awake episode of 5 rats during $60 \mathrm{~min}$, with the S.E.M. indicated by a bar. ${ }^{* * P<0.01 ~ v s}$ vehicle control (ANOVA). the serotonergic neurons in the brain had been degenerated by an intracerebroventricular injection of 5,7dihydroxytriptamine (35), except for the minimum effective dose of $4 \mathrm{mg} / \mathrm{kg}$ (Table 3 ). No abnormal behavior was observed throughout the recording period at any dose tested.

\section{Discussion}

RS-1259 is the first reported compound that inhibits both AChE and SERT in the brain following oral administration. The balanced inhibition of AChE and SERT by RS-1259 demonstrated the unique property of this compound and its potentially high efficacy in vivo. RS-1259 showed little affinity to various transporters including NA, DA, and choline transporters; to receptors including cholinergic and monoaminergic receptors; and to ChAT in vitro. A single oral administration of RS-1259 inhibited AChE and SERT in the central nervous system in a similar time frame, as expected. 
Table 3. Effects of RS-1259 on the daytime consciousness level in the intact rats and serotonergic denervated rats with 5,7-DHT

\begin{tabular}{lccc}
\hline & & \multicolumn{2}{c}{ Awake episode $(\mathrm{min})$} \\
\cline { 3 - 4 } & Dose $(\mathrm{mg} / \mathrm{kg})$ & Intact rats $(\mathrm{n}=5)$ & 5,7 -DHT-treated rats $(\mathrm{n}=5)$ \\
\hline Vehicle & - & $51.0 \pm 5.4$ & $101.0 \pm 7.4$ \\
RS-1259 & 1 & $76.2 \pm 6.0$ & Not tested \\
& 2 & $82.4 \pm 9.3^{*}$ & $131.2 \pm 13.0$ \\
& 4 & $106.6 \pm 9.8^{* *}$ & $155.4 \pm 7.3^{+\dagger}$ \\
\hline
\end{tabular}

Numbers represent the mean of total time of awake episodes in the period of $180 \mathrm{~min}$ after a single oral administration of RS-1259, with the S.E.M. ${ }^{*} P<0.05$, ${ }^{* *} P<0.01$ vs vehicle control in the intact rats. ${ }^{\dagger} P<0.01 v s$ vehicle control in 5,7-DHT treated rats. The statistical differences were calculated in each group of intact and 5,7-DHT-treated rats independently with Dunnett's $t$-test.

Both the ex vivo measurements of AChE and SERT inhibition and the microdialysis experiment indicated that RS-1259 was 3-4 times weaker than donepezil and almost equipotent to fluoxetine in exerting central cholinergic and serotonergic effects, respectively.

RS-1259 was as effective as the serotonin-selective re-uptake inhibitors in the 5-HTP enhancement test in mice, suggesting an anti-depressant effect could be expected of the compound. It was somewhat surprising that RS-1259 was effective at doses lower than the effective dose of fluoxetine, since the potencies of both compounds were similar in the ex vivo measurement of SERT inhibition in the brain. Such low doses of RS-1259 alone did not increase the locomotor activity in mice and fluoxetine-induced 5-HTP enhancement was not affected by a co-administration of donepezil at doses that do not induce cholinergic symptoms. The above inconsistency may be due to the difference in the pharmacokinetic properties between RS-1259 and fluoxetine. The doses of RS-1259 and donepezil eliciting similar increases of $\mathrm{ACh}$ in the hippocampus correlated well with their $\mathrm{ED}_{50}$ for the ex vivo inhibition of brain AChE. An oral dose four times higher than donepezil was necessary for RS-1259 to achieve a similar inhibition level of the brain AChE in mice and rats. Thus, it was concluded that the potency of RS-1259 following oral administration was approximately a quarter of that of donepezil with respect to AChE inhibition, whereas it was equipotent to fluoxetine with respect to SERT inhibition in the central nervous system in vivo.

It has been reported that not only cholinergic but also serotonergic impairments in the brain are involved in causing cognitive deficits in aged animals (36) and in humans (37). The effectiveness of RS-1259 in improving these deficits related to the central nervous system was compared to that of donepezil by evaluating two models, i.e., memory deficits in aged rats and the daytime consciousness level of rats with nocturnal habits (38). In the memory test, both RS-1259 and donepezil ameliorated the low TPT performance of aged rats, but the effective dose of RS-1259 was approximately four times higher than that of donepezil, suggesting that no advantage was obtained by a dual activation of cholinergic and serotonergic transmissions over a solely cholinergic activation in the brain with respect to memory enhancement. TPT is reported to be highly sensitive to cholinergic deficits (30). We failed to observe any increase in extracellular levels of ACh and 5HT in the rat hippocampus by fluoxetine and donepezil, respectively, even at high doses. A positive interaction between cholinergic and serotonergic transmissions in the central nervous system may not exist, at least not in the hippocampus. A higher TPT score by RS-1259 was probably obtained solely by improvements in the cholinergic transmission and not the serotonergic one. The simultaneous serotonergic activation by RS-1259 seemed not to affect the cholinergic transmission involved in the memory system.

The consciousness level is associated with several neurotransmitter systems in the brain including cholinergic and serotonergic systems. Dringenberg and Diavolitsis (39) reported that a co-activation of the cortical cholinergic and serotonergic transmissions restored the EEG activation abolished by a monoaminergic-cholinergic blockade. The authors used a complicated pharmacological procedure to induce the blockade and a co-activation of cholinergic and serotonergic transmissions in the cortex, without considering any possible drug-drug interaction between the compounds used. Using the dual inhibitor of $\mathrm{AChE}$ and SERT, we were able to evaluate the pharmacological effects of a simultaneous activation of both cholinergic and serotonergic transmissions in the brain without having to take into account any drug-drug interaction. We compared the effect of RS-1259 with that of don- 
epezil on the daytime consciousness level of rats, which is low when they are in a familiar surrounding. Both compounds increased the consciousness level at similar doses. Considering the fact that RS-1259 inhibited brain $\mathrm{AChE}$ with a potency four times weaker than that of donepezil, this result clearly indicates that a simultaneous activation of the central serotonergic system could reduce the dose of $\mathrm{AChE}$ inhibitor needed to maintain an active consciousness level. This notion was confirmed by the observation that a larger dose of RS-1259 was required for the elevation of consciousness level in rats subjected to serotonergic denervation than that in normal rats.

In summary, an orally active dual inhibitor of AChE and SERT, RS-1259, was newly synthesized. Using this dual inhibitor, we confirmed that the degree of cholinergic activation required in maintaining the brain active could be reduced by a concurrent activation of the central serotonergic transmission. Thus, it is anticipated that cognitive disorders such as AD would be effectively and safely treated with dual inhibitors of AChE and SERT.

\section{Acknowledgments}

The authors greatly appreciate Mr. A. Hirai, Ms. K. Takayama, and Ms. Y. Kazari for their excellent technical support.

\section{References}

1 Davis P, Maloney AJ. Selective loss of central cholinergic neurons in Alzheimer disease. Lancet. 1976;2(8000):1403.

2 White P, Hiley CR, Goodhardt MJ, et al. Neocortical cholinergic neurons in elderly people. Lancet. 1977;1(8013):668-671.

3 Summers WK, Majovski LV, Marsh GM, Tachiki K, Kling A. Oral tetrahydroaminoacridine in long-term treatment of senile dementia, Alzheimer's type. N Engl J Med. 1986;315:12411245.

4 Rogers SL, Farlow MR, Doody RS, Mohs R, Friedhoff LT. A 24-week, double-blind, placebo-controlled trial of donepezil in patients with Alzheimer's disease. Donepezil Study Group. Neurology. 1998;50:136-145.

5 Forette F, Anand R, Gharabawi G. A phase II study in patients with Alzheimer's disease to assess the preliminary efficacy and maximum tolerated dose of rivastigmine (Exelon). Eur J Neurol. 1999;6:423-429.

6 Wilcock GK, Lilienfeld S, Gaens E. Efficacy and safety of galantamine in patients with mild to moderate Alzheimer's disease: multicentre randomised controlled trial. Galantamine International-1 Study Group. Br Med J. 2000;321:1445-1449.

7 Nordberg A, Svensson AL. Cholinesterase inhibitors in the treatment of Alzheimer's disease: a comparison of tolerability and pharmacology. Drug Safety. 1998;19:465-480.

8 Wenk GL, Pierce DJ, Struble RG, Price DL, Cork LC. Age- related changes in multiple neurotransmitter systems in the monkey brain. Neurobiol Aging. 1989;10:11-19.

9 Palmer AM, DeKosky ST. Monoamine neurons in aging and Alzheimer's disease. J Neural Transm. 1993;91:135-159.

10 Rossor M, Iversen LL. Non-cholinergic neurotransmitter abnormalities in Alzheimer's disease. Br Med Bull. 1986;42:70 74.

11 Decker MW, McGaugh JL. The role of interactions between the cholinergic system and other neuromodulatory systems in learning and memory. Synapse. 1991;7:151-168.

12 Berger AK, Fratiglioni L, Forsell Y, Winblad B, Backman L. The occurrence of depressive symptoms in the preclinical phase of AD: a population-based study. Neurology. 1999;53:19982002.

13 Harwood DG, Sultzer DL, Wheatley MV. Impaired insight in Alzheimer disease: association with cognitive deficits, psychiatric symptoms, and behavioral disturbances. Neuropsychiatry Neuropsychol Behav Neurol. 2000;13:83-88.

14 Sweet RA, Nimgaonkar VL, Devlin B, Lopez OL, DeKosky ST. Increased familial risk of the psychotic phenotype of Alzheimer disease. Neurology. 2002;58:907-911.

15 Mendez MF, Martin RJ, Smyth KA, Whitehouse PJ. Psychiatric symptoms associated with Alzheimer's disease. J Neuropsych Clin Neurosci. 1990;2:28-33.

16 Nyth AL, Gottfries CG. The clinical efficacy of citalopram in treatment of emotional disturbances in dementia disorders. A Nordic multicentre study. Br J Psychiatry. 1990;157:894-901.

17 Burke WJ, Dewan V, Wengel SP, Roccaforte WH, Nadolny GC, Folks DG. The use of selective serotonin reuptake inhibitors for depression and psychosis complicating dementia. Int J Ger Psychiatry. 1997;12:519-525.

18 Lyketsos CG, Sheppard JM, Steele CD, et al. Randomized, placebo-controlled, double-blind clinical trial of sertraline in the treatment of depression complicating Alzheimer's disease: initial results from the Depression in Alzheimer's Disease study. Am J Psychiatry. 2000;157:1686-1689.

19 Street JS, Clark WS, Gannon KS, et al. Olanzapine treatment of psychotic and behavioral symptoms in patients with Alzheimer disease in nursing care facilities: a double-blind, randomized, placebo-controlled trial. The HGEU Study Group. Arch Gen Psychiatry. 2000;57:968-976.

20 McRae T, Griesing T, Whalen E. Donepezil and sertraline for the management of behavioral symptoms in patients with Alzheimer's disease. Neurology. 2000;54 Suppl 3:A416.

21 Hemeryck A, Belpaire FM. Selective serotonin reuptake inhibitors and cytochrome P-450 mediated drug-drug interactions: an update. Curr Drug Metab. 2002;3:13-37.

22 Jann MW, Shirley KL, Small GW. Clinical pharmacokinetics and pharmacodynamics of cholinesterase inhibitors. Clin Pharmacokinet. 2002;41:719-739.

23 Kogen H, Toda N, Tago K, et al. Design and synthesis of dual inhibitors of acetylcholinesterase and serotonin transporter targeting potential agents for Alzheimer's disease. Org Lett. 2002;4:3359-3362.

24 Hirai K, Kato K, Nakayama T, et al. Neurochemical effects of 3-[1-(phenylmethyl)-4-piperidinyl]-1-(2,3,4,5-tetrahydro- $1 H$-1benzazepin-8yl)-1-propanone fumarate (TAK-147), a novel acetylcholinesterase inhibitor, in rats. J Pharmacol Exp Ther. 1997;280:1261-1269.

25 McKenna MT, Proctor GR, Young LC, Harvey AL. Novel 
tacrine analogues for potential use against Alzheimer's disease: potent and selective acetylcholinesterase inhibitors and 5-HT uptake inhibitors. J Med Chem. 1997;40:3516-3523.

26 Kaneko T, Hara T, Abe K, et al. Pharmacological properties of RS-1259, an orally active dual inhibitor of acetylcholinesterase and serotonin uptake. Pharmacologist. 2002;44 Suppl 1:A255.

27 Ellman GL, Courtney D, Andres V Jr, Featherstone RM. A new and rapid colorimetric determination of acetylcholinesterase activity. Biochem Pharmacol. 1961;7:88-95.

28 Paxinos G, Watson C. The Rat Brain in Stereotaxic Coordinates. 2nd ed. San Diego, CA: Academic Press; 1986.

29 Kikusui T, Tonohiro T, Kaneko T. Simultaneous evaluation of spatial working memory and motivation by the allocentric place discrimination task in the water maze in rats. J Vet Med Sci. 1999;61:673-681.

30 Kikusui T, Tonohiro T, Kaneko T. The allocentric place discrimination task is selectively and highly dependent on the central muscarinic system in rats. Pharmacol Biochem Behav. 2000;65:131-139.

31 Kikusui T, Tonohiro T, Kaneko T. Age-related working memory deficits in the allocentric place discrimination task: possible involvement in cholinergic dysfunction. Neurobiol Aging. 1999;20:629-636.

32 Fifkova E, Marsala J. Stereotaxic atlas for the cat, rabbit and rat. In: Petran BJ, Zachar J, editors. Electrophysiological Methods in Biological Research. New York-London: Academic Press; 1967. p. 653-731
33 Mitrushina M, Drebing C, Uchiyama C, Satz P, Van Gorp W, Chervinsky. The pattern of deficit in different memory components in normal aging and dementia of Alzheimer's type. J Clin Psychol. 1994;50:591-596.

34 Markowska AL, Price D, Koliatsos VE. Selective effects of nerve growth factor on spatial recent memory as assessed by a delayed nonmatching-to-position task in the water maze. J Neurosci. 1996;16:3541-3548.

35 Björklund A, Baumgarten HG, Rensch A. 5,7 Dihydroxytryptamine: improvement of its selectivity for serotonin neurons in the CNS by pretreatment with desipramine. J Neurochem. 1975;24:833-835.

36 Richter-Levin G, Segal M. Serotonin, aging and cognitive functions of the hippocampus. Rev Neurosci. 1996;7:103-113.

37 Porter RJ, Lunn BS, Walker LL, Gray JM, Ballard CG, O’Brien JT. Cognitive deficit induced by acute tryptophan depletion in patients with Alzheimer's disease. Am J Psychiatry. 2000;157: 638-640.

38 Iwata N, Kozuka M, Hara T, et al. Activation of cerebral function by CS-932, a functionally selective M1 partial agonist: neurochemical characterization and pharmacological studies. Jpn J Pharmacol. 2000;84:266-280.

39 Dringenberg AC, Diavolitsis P. Electroencephalographic activation by fluoxetine in rats: role of 5-HT1A receptors and enhancement of concurrent acetylcholinesterase inhibitor treatment. Neuropharmacology. 2002;42:154-161. 